\title{
TRENDS IN THE CODE DESIGN OF STEEL FRAMED STRUCTURES
}

\author{
N.S. Trahair \\ Emeritus Professor of Civil Engineering \\ The University of Sydney \\ (Corresponding author: E-mail:_nicholas.trahair@gmail.com)
}

Received: 3 September 2016; Revised: 13 February 2017; Accepted: 16 February 2017

\begin{abstract}
This paper surveys trends in the design of steel framed structures under quasi-static loads with reference to design codes such as the US AISC Specification, the UK BS5950, the Australian AS4100, the European EC3, and the Hong Kong Code of Practice.

The paper provides a brief timeline of the development of steel design codes over the past 80 years, summarises the methods of design now permitted in codes, discusses some of the shortcomings of present codes, and suggests future areas for improvement.

It is concluded that future design codes might allow the use of purpose-built computer programs which can provide accurate predictions of member strength, and might only describe the characteristics of the methods of structural analysis and the member design strengths which may be used. Such a code would have some of the present member strength inaccuracies and shortcomings removed and allow them to be replaced by the use of more accurate advanced analysis computer programs.
\end{abstract}

Keywords: Analysis, codes, design, frames, steel, structures

DOI: $10.18057 /$ IJASC.2018.14.1.3

\section{INTRODUCTION}

This paper surveys trends in the design of steel framed structures under quasi-static loads with reference to design codes such as those of the US [1], the UK [2], Australia [3], Europe [4], and Hong Kong [5].

The development of design codes relies heavily on experience and on the theoretical and experimental findings of research studies. The steady and now rapid increase in these has lead to significant expansions in the guidance provided by codes. It is worth noting that an unexpected consequence of these expansions is that it becomes increasingly more onerous to revise and update design codes.

The following sections provide a brief timeline of the development of design codes over the past 80 years, summarises the methods of design now permitted in codes, discusses some of the shortcomings of present design codes, and suggests future areas for improvement.

\section{A TIMELINE FOR STEEL DESIGN CODES}

Steel design codes in the 1930's were working stress codes in which the member stresses determined by analysing the frame structure under the quasi-static working loads were required to be less than the permissible working stresses set out in the codes. Analysis of all but statically determinate frames (Figure 1) was difficult, because the established methods of indeterminate 
analysis were time consuming and error prone for many practical structures. Instead, approximate methods were used such as those which relied on assumed points of contra-flexure to render the structure statically determinate, or the moment distribution method developed by Hardy-Cross. Limited and relatively simple and sometimes empirical approximations were given for the permissible working stresses which made allowances for buckling, initial crookedness, and yielding, and incorporated factors of safety of the order of 2 .

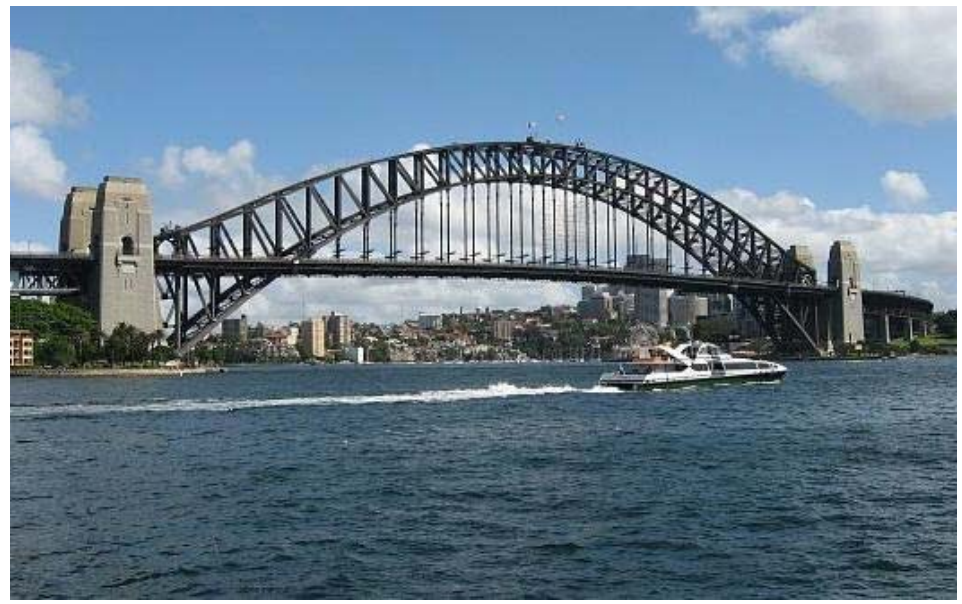

Figure 1. A Structure Designed Manually

This situation continued until the 1960's, when plastic analysis and design were permitted. At this time, factors of safety were reduced, and more accurate expressions were used for the permissible working stresses which allowed for a wider range of restraint conditions for beams and columns which fail by buckling. The 1968 predecessor of [3] allowed a method of design by buckling analysis in which the results of analyses for the elastic lateral buckling of beams could be used directly in determining the allowable stresses. Although computers were being used by researchers, they had little impact on designers.

The development of formulations for the permissible working stresses continued until the introduction of limit states design codes in the 1980's and 1990's, in which the analysis and design for strength moved from the working towards the ultimate load level. This required a more careful assessment of stability effects at these higher loads, and more accurate assessments of the strength design capacities of members and connectors.

The 1990 predecessor of [3] contained for the first time a section which distinguished among the different types of analysis that were permitted, including first-order elastic analysis, amplified firstorder analysis, second-order elastic analysis, and elastic buckling analysis, as well as plastic analysis. Design methods varied according to the method of analysis used.

The code recognized that designers were increasingly using computer methods of elastic analysis. It also recognized that design strength formulations could become more detailed, because the widespread use of computers would lead to these formulations being programmed, and even linked directly to computer analysis programs.

This predecessor also introduced the concept of advanced analysis, in which the previously separate activities of analysing the structure to determine the member actions and of designing suitable members to resist those actions was replaced by a single analysis of the structure which included all the effects that affect member strength. 
Later codes have continued the process of making their member strength formulations more detailed.

\section{PRESENT METHODS OF ANALYSIS AND DESIGN}

\subsection{Methods of Structural Analysis.}

In most methods of analyzing frame structures under quasi-static loads, each member is represented as a single line element, and the distribution of forces and moments throughout the frame is determined by using the conditions of static equilibrium and of geometric compatibility between the members at the joints. The way in which this is done depends on whether a frame is statically determinate (in which case the complete distribution of forces and moments can be determined by statics alone), or is statically indeterminate (in which case the compatibility conditions for the deformed frame must also be used before the analysis can be completed).

A statically indeterminate frame can be analysed approximately if a sufficient number of assumptions are made about its behaviour to allow it to be treated as if determinate. One method of doing this is to guess the locations of points of zero bending moment and to assume there are frictionless hinges at a sufficient number of these locations that the member forces and moments can be determined by statics alone.

The accurate analysis of statically indeterminate frames is complicated by the interaction between members: the equilibrium and compatibility conditions and the constitutive relationships must all be used in determining the member forces and moments.

There are a number of different types of analysis which might be made, some of which are discussed in the following sub-sections. These are identified using a set of acronyms which is exemplified by LBA (Linear Buckling Analysis) and GMNIA (Geometrically and Materially Nonlinear Analysis with Imperfections).

\subsubsection{First-order elastic analysis (LA)}

For some frames, it is common to use a first-order elastic analysis which is based on linear elastic constitutive relationships and which ignores any geometrical non-linearities and associated instability problems (Figure 2). The deformations $\left\{\Delta_{1}\right\}$ determined by such an analysis are related to the applied loads $\{Q\}$ through the linear relationships (Figure 3)

$[K]\left\{\Delta_{1}\right\}=\{Q\}$

in which $[K]$ is the stiffness matrix, and so the principle of superposition can be used to simplify the analysis. It is often assumed that axial and shear deformations can be ignored in frames whose actions are predominantly flexural, and that flexural and shear deformations can be ignored in frames whose member forces are predominantly axial.

\subsubsection{Elastic buckling analysis (LBA)}

However, a first-order elastic analysis will underestimate the forces and moments in and the deformations of a frame when instability effects are present. Some estimate of the importance of these can be obtained by making an elastic buckling analysis of the frame according to 
$\left\{\Delta_{b}\right\}^{T}\left[K-\lambda_{0} G\right]\left\{\Delta_{b}\right\}=0$

in which $\lambda_{0}$ is the buckling load factor and $[G]$ is the stability matrix for the initial forces.

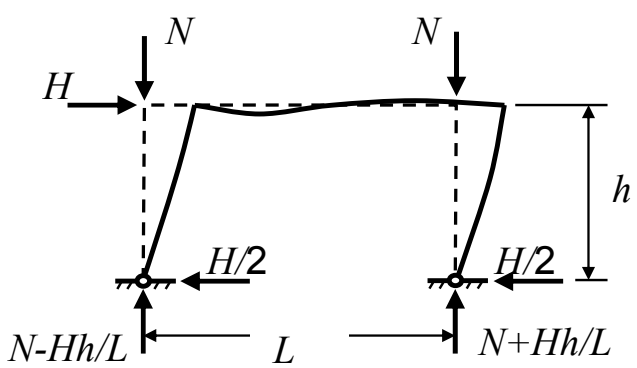

Frame

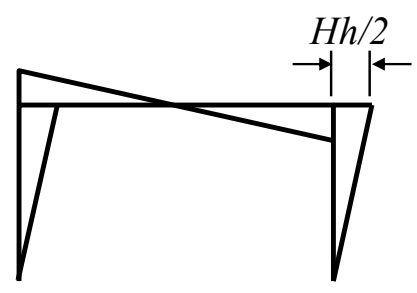

Bending moments

(a) First-order analysis

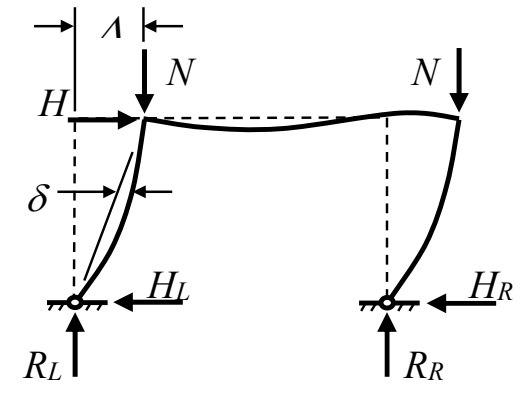

Frame

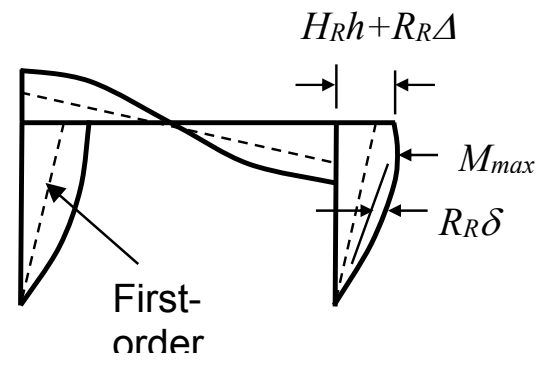

Bending moments

(b) Second-order behaviour

Figure 2. First-order Analysis and Second-order Behaviour

\subsubsection{Amplified first-order elastic analysis}

More generally, the effects of instability must be allowed for, and as a first approximation the results of an elastic first-order analysis may be amplified by using factors derived from the frame elastic buckling loads (Figure 3 ), so that

$$
\left\{\Delta_{1} \boldsymbol{a}\right\}=\left\{\Delta_{1}\right\} /\left(1-1 / \lambda_{0}\right)
$$

\subsubsection{Second-order elastic analysis (GNA)}

A more accurate allowance for the effects of instability may be made by using an elastic secondorder elastic analysis (Figures 2, 3), in accordance with

$[K-G]\left\{\Delta_{2}\right\}=\{Q\}$

While some codes $[1,3]$ allow second-order analyses to be made of the nominal frame (GNA), others $[4,5]$ require the effects of geometrical imperfections, residual stresses, and spread of plasticity to be allowed for approximately by using equivalent geometrical imperfections $\{\Delta \mathrm{i}\}$ (GNIA). The shape of these is usually taken to be the same as that of the lowest elastic buckling mode $\{\Delta b\}$ [6], while the magnitude $\alpha_{i}$ is defined in the code, so that 


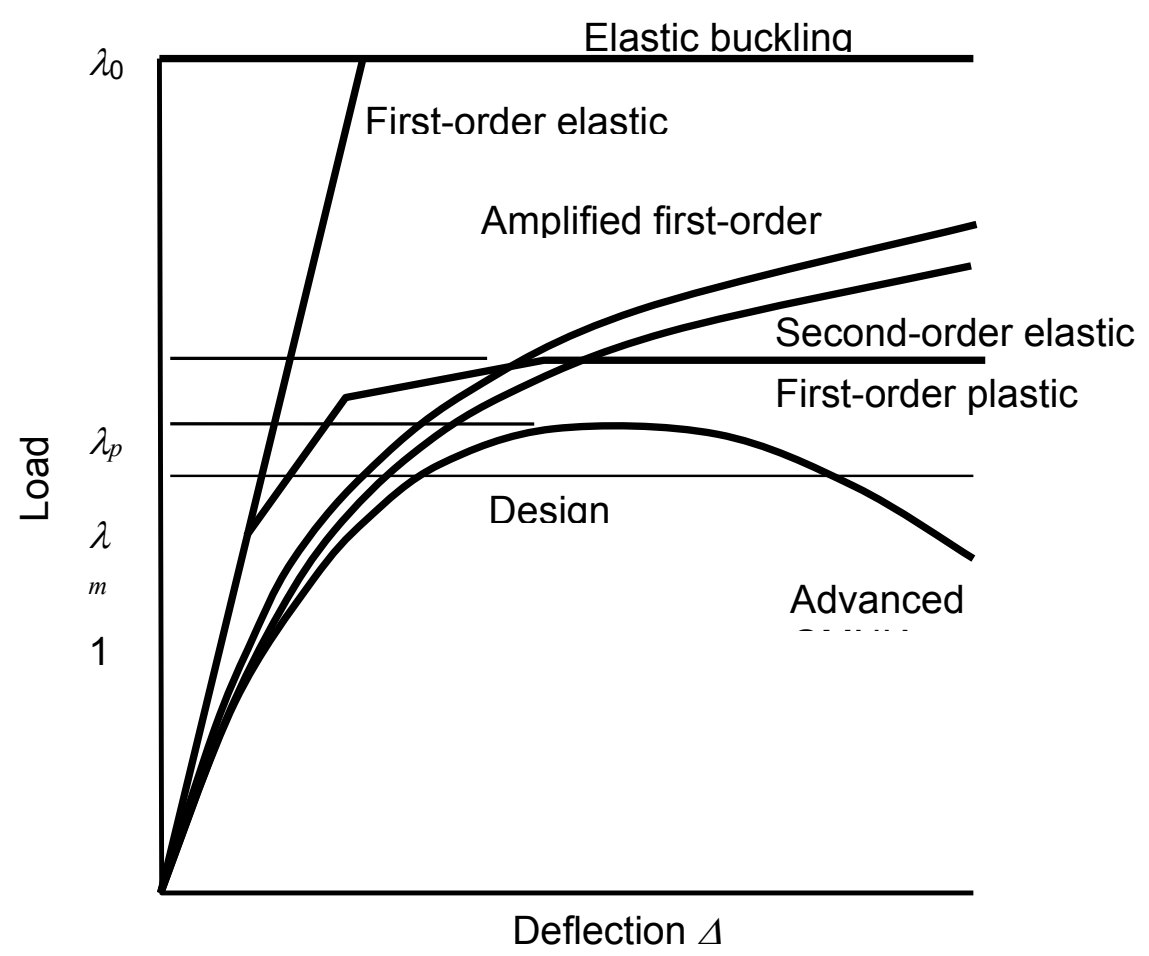

Figure 3. Methods of Analysis

$\left\{\Delta_{i}\right\}=\alpha_{i}\{\Delta b\}$

It is often convenient to replace these equivalent imperfections by equivalent (or notional) loads

$\left\{Q_{i}\right\}=[K]\left\{\Delta_{i}\right\}$

which induce first-order deformations equal to the imperfections, whence

$$
[K-G]\left\{\Delta_{2 i}\right\}=\left\{Q^{+} Q_{i}\right\}
$$

\subsubsection{Plastic analysis (MNA)}

The analysis of statically indeterminate frames near the ultimate load is further complicated by the decisive influence of the material non-linearities. Many two-dimensional (2D) frames have very small axial forces and instability effects, in which case it is comparatively easy to use a first-order plastic hinge analysis, according to which a sufficient number of plastic hinges must form to transform the frame into a collapse mechanism (Figure 3). The computational efficiency of the plastic hinge method is enhanced when the effects of geometrical non-linearities can be accurately allowed for by using one element per member [7, 8] (GMNA). Some attempts have been made to extend these plastic hinge methods to allow for semi-rigid rather than rigid joints between members $[9,10]$.

Plastic zone analyses of 2D frames for which local and lateral buckling are prevented may allow for geometric (in-plane instability) and material (yielding) non-linearities, residual stresses, and geometrical imperfections, and account for the spread of the yielded zones through the cross- 
sections and along the members of the frames [9-11]. However, while this method is extremely accurate, it is computationally comparatively complex, wasteful, and slow. Plastic zone methods have been used to develop benchmark solutions for testing the more efficient but less accurate plastic hinge methods [13 - 17], in which yielding effects are concentrated at a few cross-sections, and residual stress and geometrical imperfection effects are approximated by using reduced stiffnesses.

The plastic hinge method is simpler to use and computationally much more efficient than the plastic zone method. The results of the two methods are similar, except when the bending moment is nearly uniform with a wide spread of plasticity. In most practical cases, the plastic hinge method is considered to be adequate.

\subsubsection{Advanced analysis (GMNIA)}

In advanced analysis $[12,13,18]$, the previously separate activities of analysing the frame to determine the line element member actions and of designing suitable members to resist those actions is replaced by a single analysis of the frame which includes all those effects that affect member strength such as local and lateral buckling, geometrical imperfections, residual stresses, and inelastic behaviour. It is then only necessary for the frame to reach a stable equilibrium position under the design loads (increased by incorporating a frame capacity factor) for it to be deemed satisfactory (Figure 3).

For 2D frames for which local and lateral buckling are prevented, plastic hinge analyses which take account of in-plane stability and equivalent imperfections are equivalent to advanced analyses.

As originally envisaged, advanced analysis of steel frames was expected to be carried out by using line elements to represent the members. More generally, however, advanced analysis may also be carried out by modeling the members as assemblages of plate or shell elements, even though the greatly increased number of elements requires increased computer speeds and storage to be viable.

\subsubsection{Quasi advanced analysis for local and out-of-plane buckling}

There are a number of quasi advanced methods for the analysis of 2D frames with 2D loading which include the effects of strength reductions due to local and out-of-plane buckling. Quasi advanced methods use 2 stages instead of the single analysis stage of a true advanced analysis. First an advanced in-plane analysis is made of the frame which omits the effects of local and outof-plane buckling. For the second stage, the local and out-of-plane member strengths are checked by using either the code formulations (which conservatively ignore interactions between members) or more accurate analyses of the buckling strengths, if available.

Quasi advanced analyses are comparatively efficient when only a few line elements per member are needed for the in-plane analysis, since the larger number of elements required for accurate determinations of the local and out-of-plane strengths are avoided.

\subsection{Methods of Design}

\subsubsection{Design by code formulations}

Present code methods of design provide formulations of the design strengths which are used to check the adequacy of the members and connections to resist the actions determined by the analysis 
of the frame. Of necessity, these are often limited in their application to the most common examples such as members of doubly symmetric cross-section. In some cases, the formulations (for beam-columns) are extremely complicated [4], while in others they are very simple [1].

\subsubsection{Design by elastic buckling analysis}

Some design codes $[2,3,5]$ give advice on the effects of moment distribution, load height, and elastic restraints on the elastic lateral buckling of beams which is sometimes of somewhat doubtful accuracy, especially with respect to the effects of load height, while all codes are limited in the amount of advice on elastic buckling that they can give. This difficulty is avoided in [3], which explicitly allows the alternative method of design by elastic buckling analysis [19] in which accurate values of the elastic buckling moment $M_{0}$ are used directly in the design process to determine the nominal design capacity $M d$. This allows computer programs such as PRFELB [20, 21 ] to be used to obtain accurate values of the elastic buckling moment $M_{0}$ which account properly for the effects of moment distribution, load height and end restraints.

In [3], the lateral buckling design of beams is founded on a basic beam design curve which reduces the elastic buckling moment $M_{0} u$ of a simply supported beam in uniform bending. This is achieved by using slenderness reduction factors

$$
\alpha_{s}=0.6\left\{\sqrt{\left[\left(\frac{M_{s}}{M_{0 u}}\right)^{2}+3\right]-\left(\frac{M_{s}}{M_{0 u}}\right)}\right\}
$$

in which $M_{s}$ is the section moment capacity, which were determined using the results of tests on full-scale members with practical values of residual stress and geometric imperfections [19].

In the method of design by elastic buckling analysis, the actual elastic buckling moment $M_{0}$ is substituted for the value $M 0 u$ for a simply supported beam in uniform bending. However this method is conservative because it does not allow for the effects of the moment distribution on inelastic buckling. This is compensated for in [3] by using a moment modification factor

$\alpha_{m}=M_{0 s} / M_{0 u}$

in which $M_{0 u}$ is the elastic buckling moment of a beam which is unrestrained against lateral rotation and loaded at the shear centre. The nominal design capacity is then determined from

$$
M_{d}=\alpha_{m} \alpha_{s} M_{s} \leq M_{s}
$$

The method of design by buckling analysis is demonstrated in Figure 4 for the example of the lateral buckling of simply supported beams under moment gradient.

The European code [4] gives no advice on elastic lateral buckling, but requires the direct use of $M_{0}$ in the design process. This implicitly requires the use of the method of design by buckling analysis. The method of design by elastic buckling analysis is also required by [4] for the design of compression members, while [3] allows this method to be used for non-uniform compression members. 


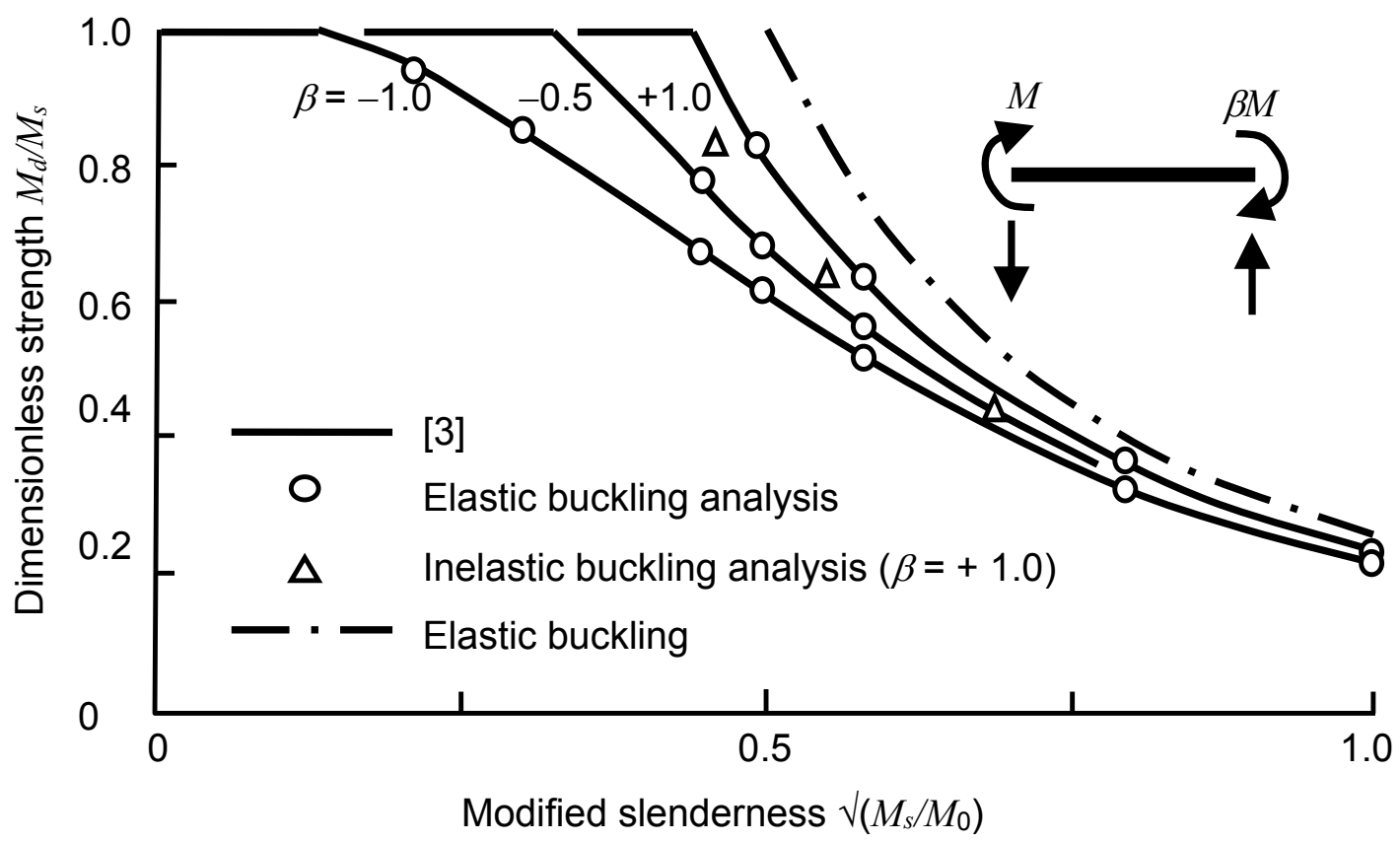

Figure 4. Buckling Strengths of Beams under Moment Gradient

The method of design by elastic buckling analysis is also used as the Direct Strength Method for the design of cold-formed steel members against local buckling, distortional buckling [22], and flexural, torsional and flexural-torsional member buckling in [23, 24].

\subsubsection{Out-of-plane design by inelastic buckling analysis}

In the code method of out-of-plane design by elastic buckling analysis, the results of an elastic buckling analysis which incorporates the effects of non-uniform bending, load height, and elastic restraints are used in determining slenderness reduction factors, which also make allowance for the effects of residual stresses and geometrical imperfections. However, this method does not allow for the local effects of non-uniform yielding on the inelastic lateral buckling resistance.

The inelastic out-of-plane buckling resistance of a beam under non-uniform bending is significantly affected by local reductions in the out-of-plane stiffnesses in the high moment regions of the beam where yielding takes place. Because the moment distribution varies, so do the stiffnesses, and the beam becomes non-uniform. To analyse this, account must be taken of the distribution of the elastic and inelastic regions both in the cross sections as well as along the beam.

One way to achieve this is to use the method of member strength design by inelastic buckling analysis [25] in which an elastic buckling analysis is carried out which allows for the local effects of non-uniform yielding on the out-of-plane stiffnesses by using reduced moduli $\gamma E, \gamma G$ [26]. The advantage of the method is that finite element buckling analysis programs such as PRFELB [20, 21] may be used directly without empirical adjustments of the results.

This method has been tested against code formulations [3] for the lateral buckling strengths of beams under moment gradient, beams with central concentrated loads acting away from the shear centre, and beams with elastic end restraints [25]. It has also been used for columns, beam-columns [25], frames [7], and cantilevers [28]. 
It has also been used in conjunction with the [1] formulations for column and beam strengths and brace stiffnesses $[29,30]$.

Extensive calibrations of this method against advanced analyses of the inelastic buckling strengths of beam, columns, and beam-columns have been made [31 - 34]. It has been anticipated [35] that this method will be incorporated in a future edition of [4].

The reduced elastic moduli $\gamma E, \gamma G$ used in the elastic buckling analysis to determine a reduced buckling moment $M_{0 r}$ are derived from the nominal lateral buckling design strengths $M_{d}$ for simply supported beams in uniform bending, and so include allowances for the effects of yielding, residual stresses and geometrical imperfections. For beams in uniform bending, the resultant reduced moments $M 0 r$ are equal to the design moments $M_{d}$.

The reduced moduli decrease as the bending moment increases (Figure 5), and so when they are applied to beams with non-uniform moment distributions, there are greater reductions in the high moment regions and smaller or no reductions in the low moment regions. The method thus takes account of the effect of the moment distribution on inelastic lateral buckling.

The results of using the method of design by inelastic buckling analysis has been used to determine the nominal [3] design strengths $M_{d}=M_{0}$ of simply supported beams under moment gradient are shown in Figure 4.

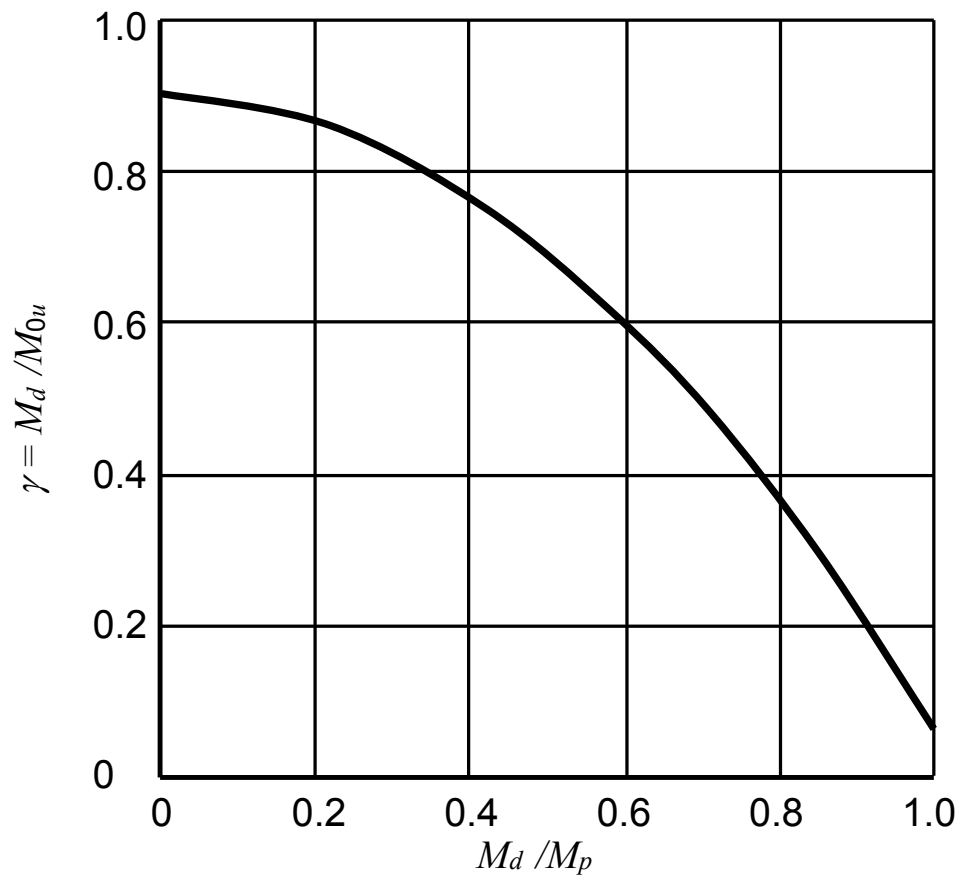

Figure 5. Reduced Elastic Moduli Factors

\subsubsection{Design by advanced analysis}

When using advanced analysis, the design criterion may be expressed as

$\lambda_{m} \geq 1 / j_{s}$ 
where $\lambda_{m}$ is the maximum value of the load factor at failure (Figure 3) determined by repeated analysis and $j_{s}$ is the system resistance factor (equivalent to the frame capacity factor) which may be obtained from a reliability analysis of the structural system. In the design situation where the design loads are known ( $\lambda=1$ in Figure 3$)$, this criterion further simplifies to the frame being satisfactory when the advanced analysis shows that the frame is in equilibrium under the load set defined by $\lambda=1 / j_{s}$, which obviates the repeated analysis needed to determine $\lambda_{m}$

In the original formulation for design by advanced analysis [3], the analysis is carried out at the design load level $(\lambda=1)$ and the frame is satisfactory if none of the design member section and connection capacities are exceeded. This method provides an approximate alternative to using the system resistance factor $j_{s}$.

Research has been conducted in recent years to determine system resistance factors $j_{s}$ for 2D steel frames with compact cross-sections [36] and cold-formed steel frames with slender cross-sections [37], suggesting that the system resistance factor $j_{s}$ typically lies in the range 0.8-0.9 depending on the structural system and target reliability. Design by advanced analysis provisions were included in the 2012 revision of the Australian Standard for rack structures [38] and have been implemented in the current draft of the revised Australian Cold-formed Steel Structures Standard [23]. Design by advanced analysis is also permitted in Appendix 1 of the AISC Specification [1], where the system resistance factor $j_{s}$ is implicitly incorporated by reducing the yield stress $F_{y}$ and stiffness $E$ by a factor of 0.9. A justification of this approach is given in [39].

\section{SHORTCOMINGS IN CODE METHODS OF DESIGN}

\subsection{Local Buckling Strength}

Code rules for local buckling strength are usually based on the behaviour of isolated plates, and while there are some approximations for allowing for the increased strengths that arise when the critical plate elements are restrained by others in the member cross-section, these are of somewhat doubtful accuracy.

\subsection{Compression Members}

While some code formulations of compression member strength already incorporate the results of elastic buckling analyses, there are many important situations that are not catered for, and so codes are generally inadequate in the advice that they give.

In some codes, the possibility of torsional or flexural-torsional buckling of compression members [40] is not covered directly. For example, cruciforms may fail torsionally, while angles, tees and some channels are susceptible to flexural-torsional buckling. While the method of design by elastic buckling analysis in some codes allows the actual elastic buckling load to be used directly, this may sometimes lead to strength predictions which are overly conservative, as shown in Figure 6 [41].

Compression members are frequently braced eccentrically (Figure 7) or in planes which are inclined to their principal planes, leading to flexural-torsional buckling [42]. The method of design by elastic buckling analysis may also be used in these cases. 


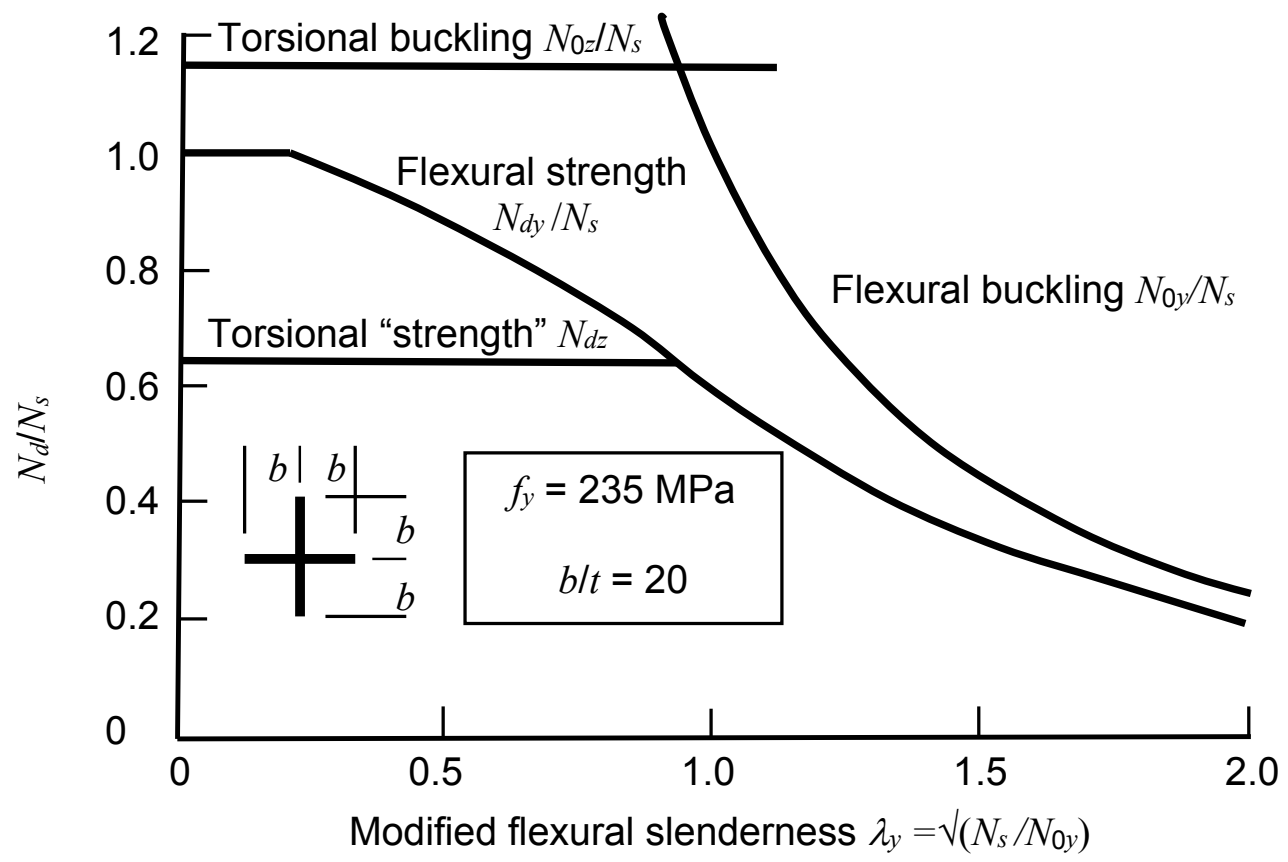

Figure 6. Design of Cruciform Columns [4]

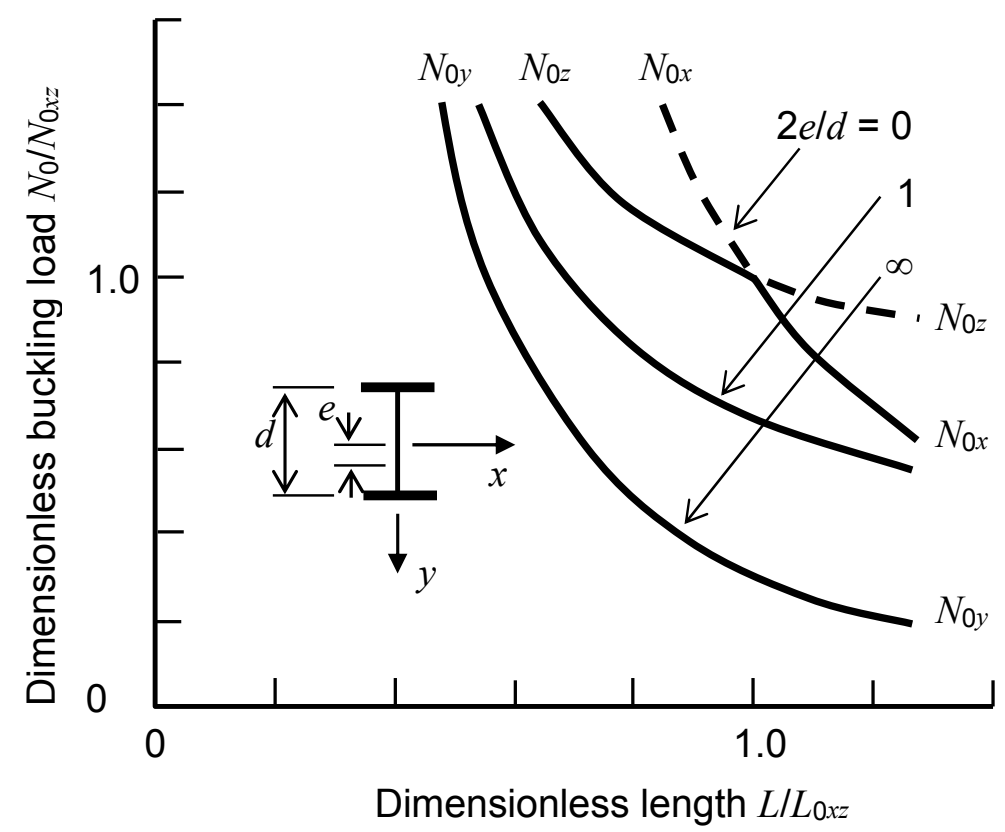

Figure 7. Buckling of Columns with Eccentric Central Restraints

Another shortcoming of some design codes is that they define rigid tolerances on compression member crookedness which prevent the use of overly crooked members (Figure 8), even when they are lightly loaded [43]. 


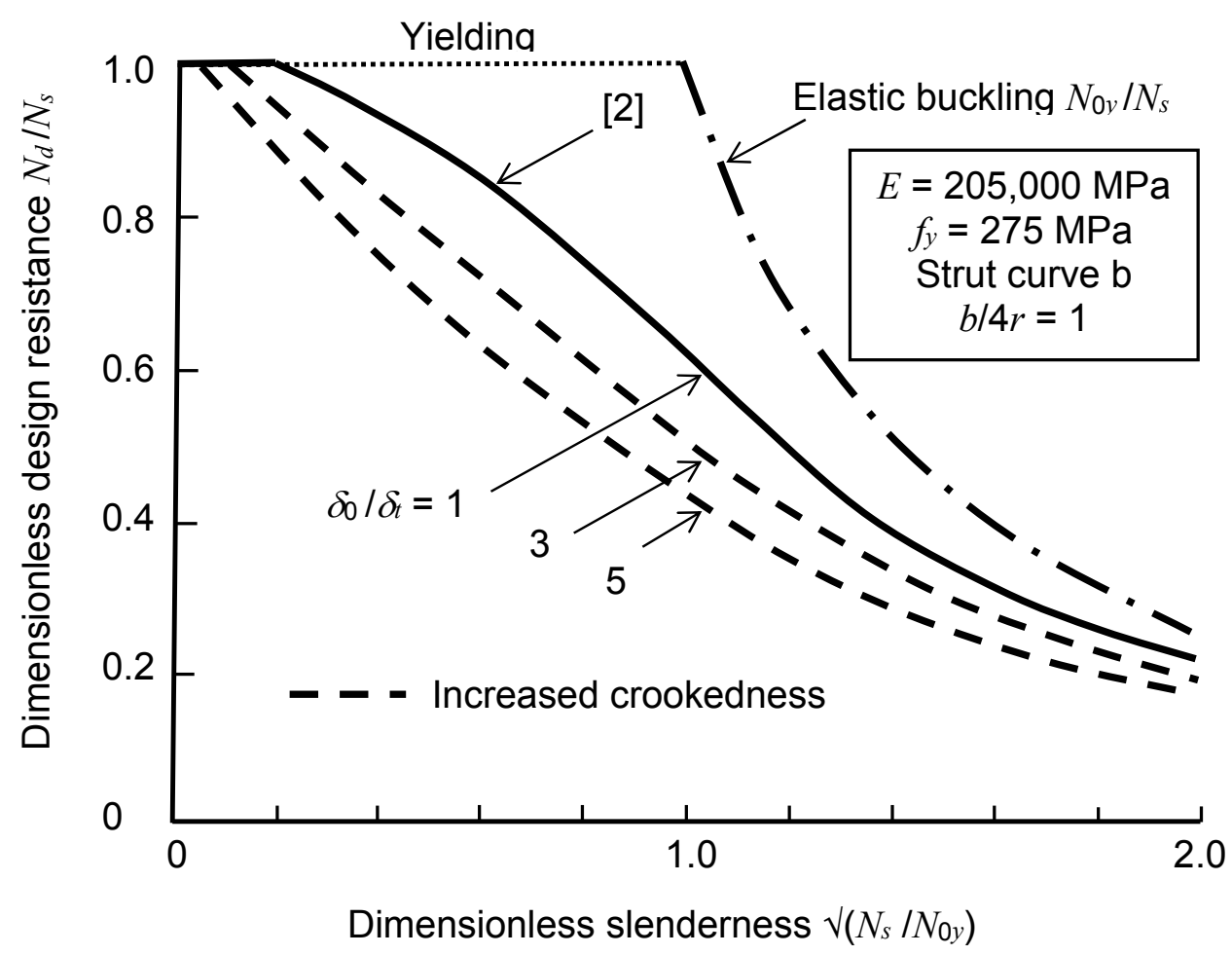

Figure 8. Design Resistances of Out-of-tolerance Columns

\subsection{Beams}

Guidance given by codes for designing beams against lateral buckling is limited, extremely variable, and mainly based on the behaviour of doubly symmetric I-beams, which may be overly conservative for other beams such as rectangular hollow sections [44, 45], as shown in Figure 9.

There are a number of common effects that modify the strength, including the geometry, the moment distribution, the load height above the shear centre, and elastic restraints [40]. More consistent designs may be achieved by using the method of design by elastic buckling analysis, but this method alone does not allow for the strengthening effects of moment gradient on inelastic buckling (Figure 4). While some codes do make allowance for these, they are often unnecessarily conservative [4].

Guidance given for the design of monosymmetric I-beams under moment gradient is often inaccurate, both in the elastic and the inelastic buckling ranges, as indicated in Figure 10 [46].

The effects of distortion on the strength of beams with slender webs are rarely covered, although the method of design by elastic buckling analysis has been used by substituting the elastic lateraldistortional buckling load for the elastic lateral buckling load. Distortion effects become important in continuous under-slung monorails, where the bottom flange cannot be restrained at intermediate supports, as shown in Figure 11 [47]. 


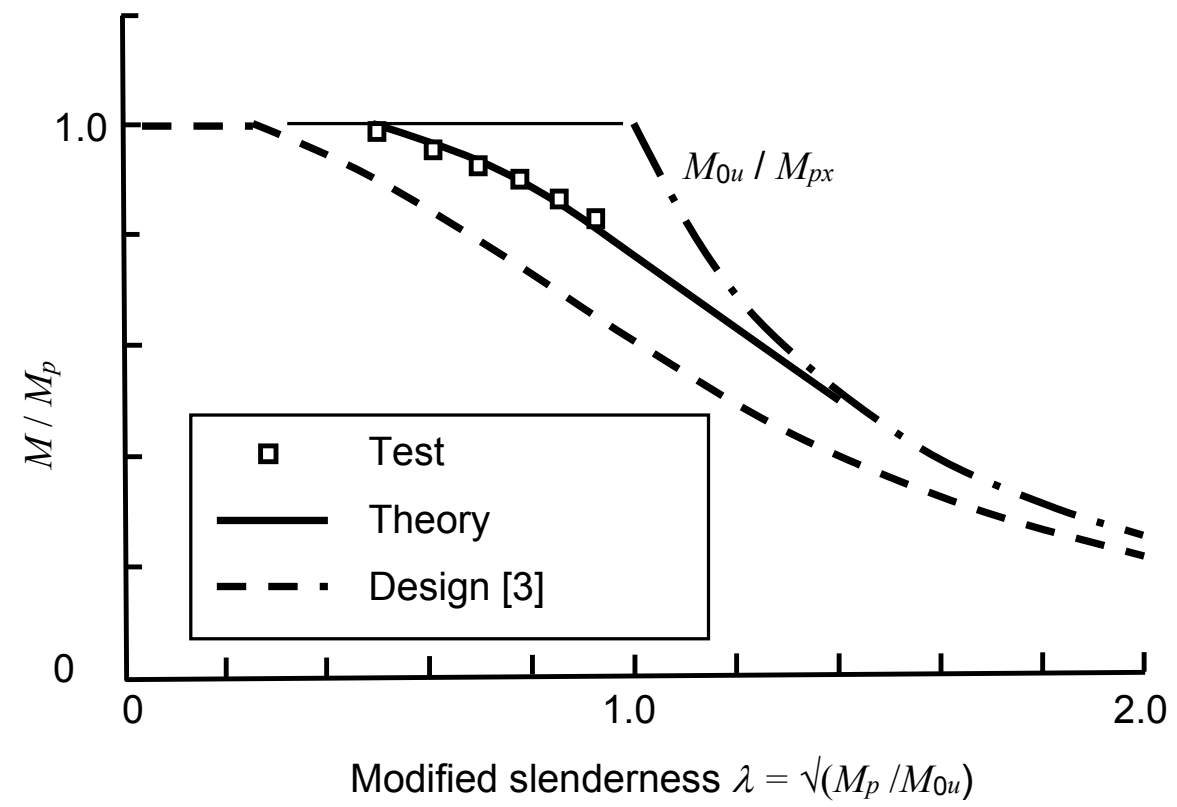

Figure 9. Lateral Buckling Strengths of RHS

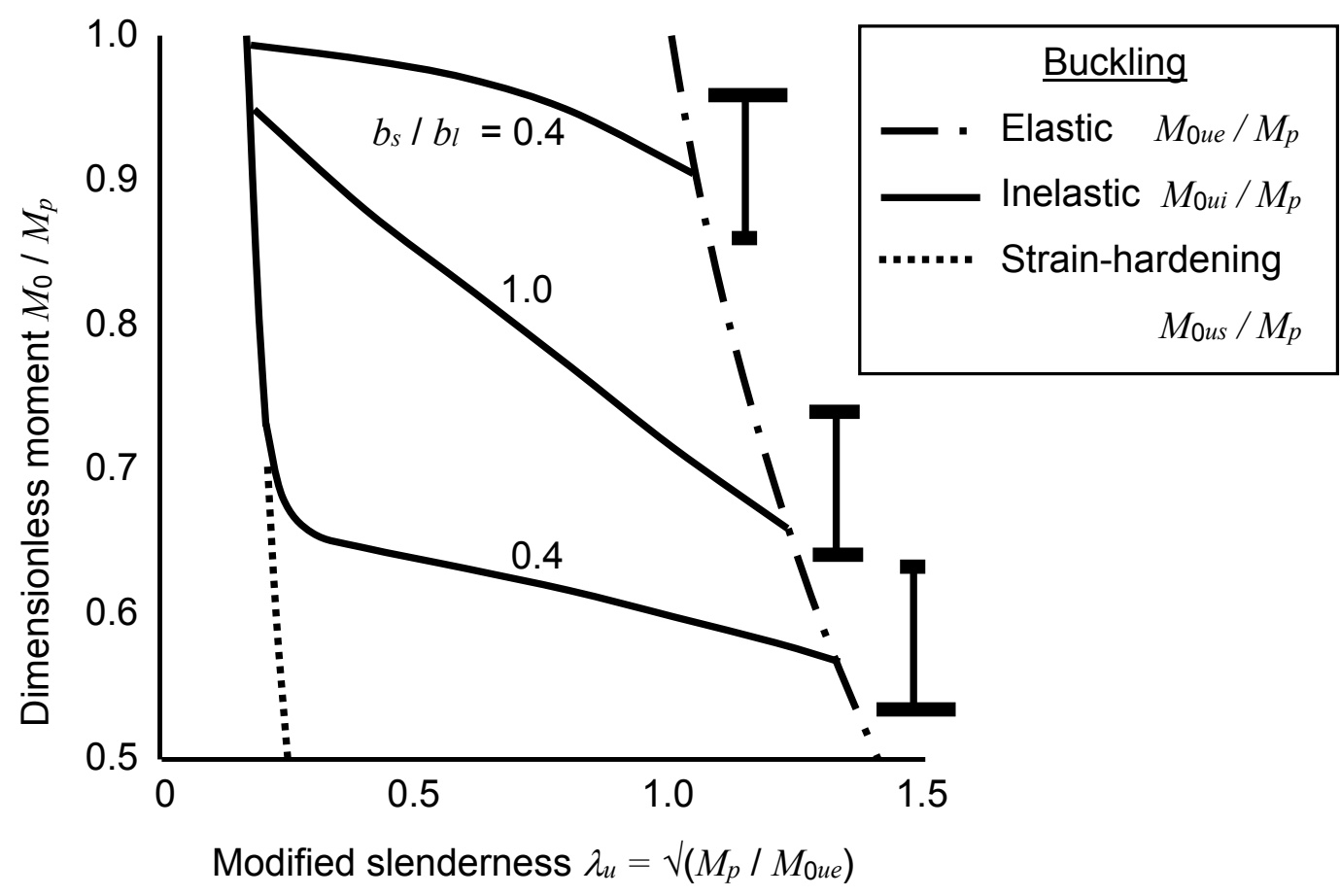

Figure 10. Inelastic buckling of monosymmetric beams - uniform bending 


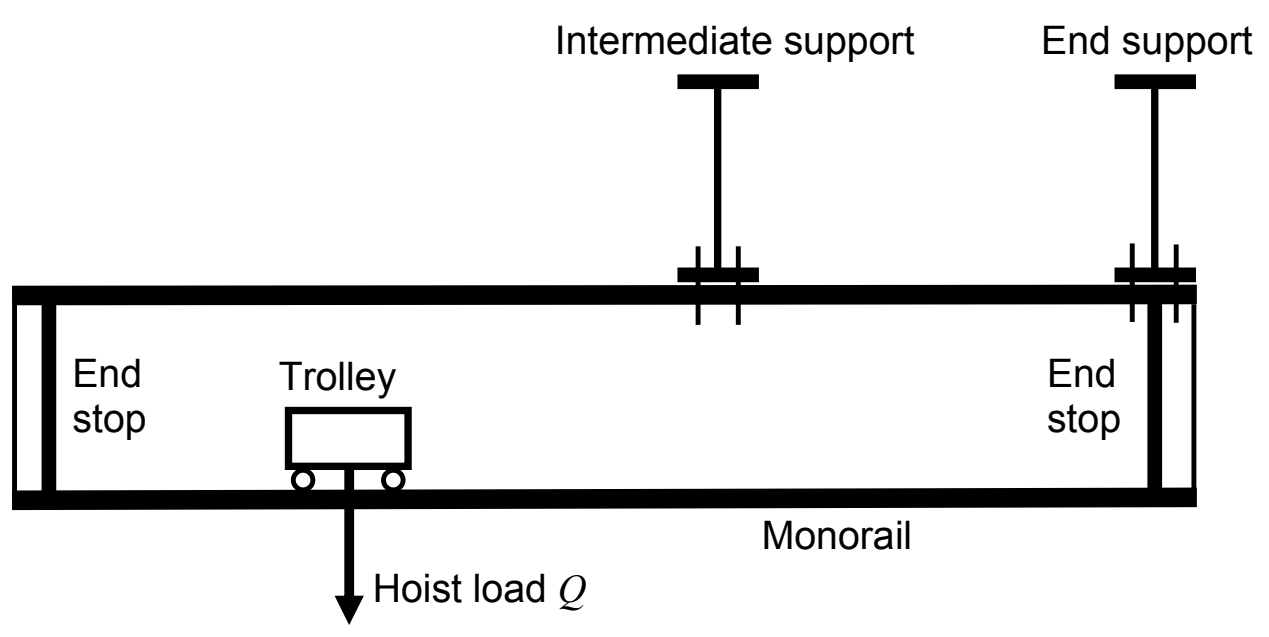

Figure 11. Overhanging Monorail
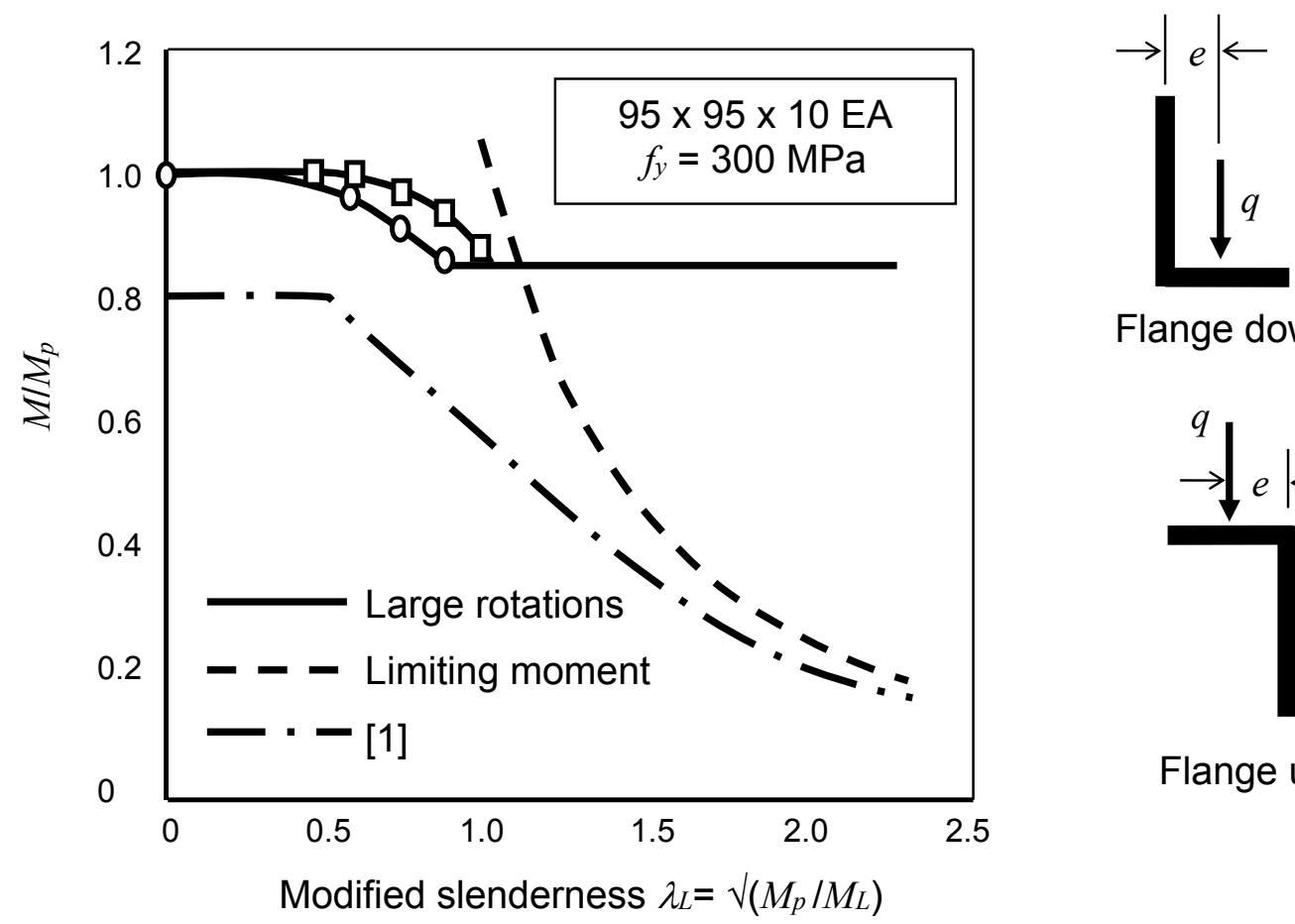

Flange down

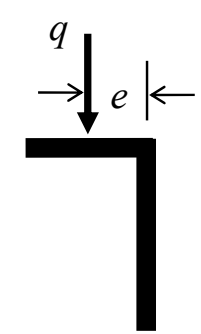

Flange up 0

Figure 12. Uniformly Loaded Equal Angle Lintel

Angle section beams are frequently loaded in biaxial bending and torsion, but code rules do not adequately reflect this behaviour, and may give rise to variable strength predictions, as shown in Figure 12 [48]. 


\subsection{Beam-Columns}

The variety of different formulations for beam-column strength [1,4] suggests that there is a corresponding lack of accuracy in their predictions of strength. Some code formulations are excessively complicated, so that manual implementation is tedious and error prone.

\subsection{Biaxial Bending and Torsion}

Torsion and combined bending and torsion is largely neglected in steel design codes, even though there is a considerable body of knowledge of the former [19], and some research studies [49] of the latter.

\subsection{Arches and Curved Girders}

The design of arches [50 - 54] and of members curved in plan [55] is not treated in design codes.

\section{FUTURE TRENDS}

\subsection{Computer Hardware}

Future analysis and design methods will be greatly influenced by further development of computer hardware and software. The expansion of storage capacity and increase in speed will allow more sophisticated structural analyses to be made of even larger structures, and will facilitate the efficient application of increasingly more complex code advice on member design. Improvements in computer speed and storage are leading to practical methods of advanced analysis for a much wider range of applications than has been the case.

At the same time there will be further developments in user-friendly pre- and post-processors for the input of data and the display of results, while there will be even greater linking of computer programs for analysis, design [56], detailing, shop drawing and manufacture. However, there will be an even stronger need for checking procedures, since data errors will propagate through linked programs (Figure 13).

\subsection{Methods of Analysis}

\subsubsection{Advanced analysis}

There have been a number of attempts to extend the method of advanced analysis of 2D frames with 2D loading to include the effects of out-of-plane and local buckling [37].

The accurate prediction of the out-of-plane strength requires the use of a finite element analysis which accounts for elastic buckling, yielding, initial crookedness, and residual stresses. The elements must be comparatively closely spaced with consequent rises in computer storage and speed requirements.

The accurate prediction of local buckling effects must account also for out-of-flatness and for postbuckling behavior. The elements must be even more closely spaced than for out-of-plane strength. 


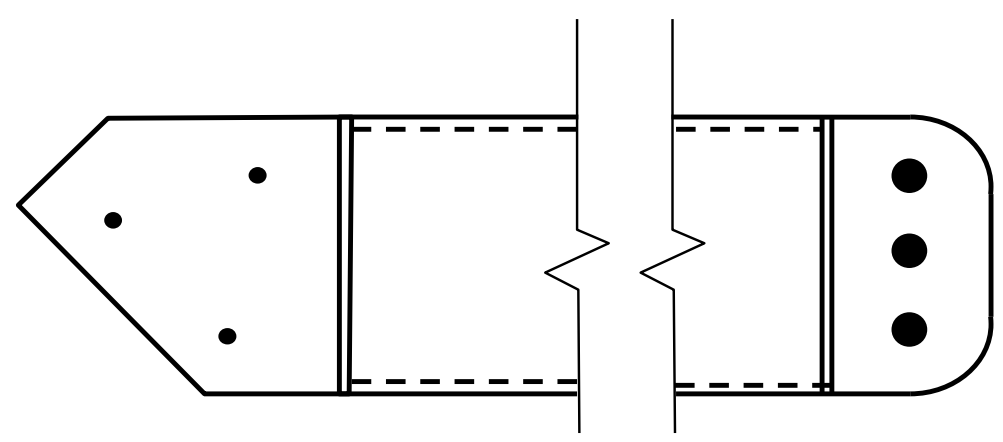

Figure 13. Computer Transmission of Errors

Advanced analysis methods which replace the member line elements with closely spaced plate or shell elements may account for all combined effects on member strength which have been difficult to represent.

\subsubsection{Analysis of biaxial bending and torsion.}

Methods of analysing biaxial bending and torsion are generally limited to first-order elastic analyses, and many of these omit the strengthening effects of warping torsion in open section members. Further difficulties arise when second-order effects must be allowed for.

\subsection{Methods of Design}

The accurate prediction of local buckling effects on member strength requires the same use of a finite element analysis as that described above for advanced analysis. Again, the elements must be closely spaced with consequent sharp rises in computer storage and speed requirements.

Torsion and combined bending and torsion are largely neglected in steel design codes, while the design of arches and members curved in plan is not treated.

\section{CONCLUSIONS}

This paper surveys trends in the design of steel framed structures under quasi-static loads with reference to design codes such as those of the US [1], the UK [2], Australia [3], Europe [4], and Hong Kong [5].

The past 80 years have seen substantial developments in analysis and design, many of which have been empowered by the development and application of computers. Working stress design has been replaced by limit states design, and second-order and advanced methods of analysis and design have been introduced, while code strength formulations have become increasingly detailed as they incorporate more and more research findings.

At present, methods of advanced analysis using line elements in which a single stage of analysis and design replace the separate stages of computer analysis and code strength design are largely restricted to 2D frames with 2D loading for which local and out-of-plane buckling are prevented. 
However, the Australian Standard AS4084 [38] for steel storage racks allows design by advanced analysis of rack structures subject to local, distortional and flexural-torsional buckling.

Quasi advanced analyses use advanced analysis of the in-plane behaviour, and code formulations for local and member out-of-plane buckling strengths. In the meantime, the adoption of the method of design by inelastic buckling analysis will allow the comparative inaccuracy of some code out-ofplane strength formulations to be bypassed.

There are a number of design code shortcomings that can be expected to be rectified in the future as more research is carried out. These include the needed for multiple beam curves for different sections such as angles, rectangular hollow sections, and monosymmetric I-sections. Further improvements are needed in the specification of beam-column strength and in the treatment of flexural-torsional buckling of columns. Situations not catered for in design codes include biaxial bending and torsion, and arches and curved girders.

A possible solution to these problems is to allow the use of purpose-built computer programs which can provide accurate predictions of member strength. Thus future design codes might only describe the characteristics of the methods of structural analysis and those of determining the design strengths of structural members which may be used. Such a code would have all the inaccuracies and shortcomings of approximating the member strengths removed and replaced by more accurate member strength computer programs.

This is already partially in place with the present practice of some codes which either allow or require design by elastic buckling analysis. An increased use of advanced finite element programs which use plate or shell elements can be anticipated.

\section{REFERENCES}

[1] American Institute of Steel Construction, "Specification for Structural Steel Buildings", 2010.

[2] British Standards Institution, "BS5950: Part 1:2000, Structural Use of Steelwork in Building, Part 1, Code of Practice for Design in Simple and Continuous Construction: Hot Rolled Sections", 2000.

[3] Standards Australia, "AS4100, Steel Structures", 1998.

[4] British Standards Institution, "Eurocode 3: Design of Steel Structures: Part 1.1 General Rules and Rules for Buildings, BS EN 1993-1-1”, 2005.

[5] The Government of the Hong Kong Special Administrative Region, Buildings Department, "GHKSAR, Code of Practice for the Structural Use of Steel", 2011.

[6] Kindmann, R. and Kraus, M., "Steel Structures Design Using FEM, Ernest and Sohn”, 2011.

[7] Chan, S.L. and Zhou, Z.H., "Second-order Elastic Analysis of Frames using Single Imperfect Element per Member", Journal of Structural Engineering, ASCE, 1995, Vol. 121, No. 6, pp. 939-45.

[8] Chan, S.L. and Zhou, Z.H., "Nonlinear Integrated Design and Analysis of Skeletal Structures", Engineering Structures, 2000, Vol. 22, No. 3, pp. 246-57.

[9] Chan, S.L., "Inelastic Post-buckling Analysis of Tubular Beam-columns and Frames", Journal of Engineering Structures, 1989, Vol. 11, pp. 23-30.

[10] Nethercot, D.A., "Frame Design Incorporating Semi-rigid Effects", Steel Construction (South Africa), 1994, Vol. 18, No. 6, pp. 24-7. 
[11] Ho, W.M.G. and Chan, S.L., "An Accurate and Efficient Method for Large Deflection Analysis of Frames with Semi-rigid Connections", Journal of Constructional Steel Research, 1993, Vol. 26, pp. 171-191.

[12] Clarke, M.J., "Plastic-zone Analysis of Frames", Advanced Analysis of Steel Frames : Theory, Software, and Applications, Chen, WF, and Toma, S, eds, CRC Press, 1994, Chapter 6, pp. 259-319.

[13] White, D.W. and Chen, W.F. (editors), "Plastic Hinge Based Methods for Advanced Analysis and Design of Steel Frames”, Structural Stability Research Council, 1993.

[14] Liew, J.Y.R., Chen, H., and Chen, W.F., "Second-order Refined Plastic Hinge Analysis of Frame Design. Parts I and II", Journal of Structural Engineering, ASCE, 1993, Vol. 119, No. 11, pp. 3196-3216, 3217-3237.

[15] Yau, C.Y. and Chan, S.L., "Inelastic and Stability Analysis of Flexibly Connected Steel Frames by the Springs-in-series Model", Journal of Structural Engineering, ASCE, 1994, Vol. 120, No. 10, pp. 2803-2819.

[16] Chan, S.L. and Chui, P.P.T., "Non-linear Static and Cyclic Analysis of Semi-Rigid Steel Frames", Elsevier Science, 2000.

[17] Liew, J.Y.R., Chen, H., Shanmugam, N.E. and Chen, W.F., "Improved Non-linear Plastic Hinge Analysis of Space Frame Structures”, Engineering Structures, 2000, Vol. 22, No. 10, pp. 1324-38.

[18] Chen, W.F. and Kim, S.E., "LRFD Steel Design Using Advanced Analysis", CRC Press, 1997.

[19] Trahair, N.S., Bradford, M.A., Nethercot, D.A. and Gardner, L., “The Behaviour and Design of Steel Structures to EC3", Taylor and Francis, 2008.

[20] Papangelis, J.P., Trahair, N.S. and Hancock, G.J., "Computer Analysis of Elastic FlexuralTorsional Buckling”, Journal of the Singapore Structural Steel Society, 1993, Vol. 4, No.1, pp. 59-67.

[21] Papangelis, J.P., Trahair, N.S. and Hancock, G.J., "Elastic Flexural-torsional Buckling of Structures by Computer", Computers and Structures, 1998, Vol. 68, pp. 125-137.

[22] Hancock, G.J., Kwon, Y.B. and Bernard, E.S., "Strength Design Curves for Thin-Walled Sections Undergoing Distortional Buckling", Journal of Constructional Steel Research, 1994, Vol. 31, 2-3, pp. 169-86.

[23] Standards Australia, "SA/NZS AS4600, Cold-Formed Steel Structures, 2005.

[24] American Iron and Steel Institute, "AISI S100-07 W/S2-10 - North American Specification For The Design Of Cold-Formed Steel Structural Members", 2007.

[25] Trahair, N.S. and Hancock, G.J., "Steel Member Strength by Inelastic Lateral Buckling", Journal of Structural Engineering, ASCE, 2004, Vol. 130, No. 1, pp. 64 - 69.

[26] Trahair, N.S. and Chan, S.L, "Out-of-plane Advanced Analysis of Steel Structures", Engineering Structures, 2003, Vol. 25, No. 13, pp. 1627 - 1637.

[27] Trahair, N.S, "Buckling Analysis Design of Steel Frames", Journal of Constructional Steel Research, 2009, Vol. 65, No. 7, pp. 1459-63.

[28] Trahair, N.S, "Steel Cantilever Strength by Inelastic Lateral Buckling", Journal of Constructional Steel Research, 2010, Vol. 66, Nos. 8-9, pp. 993-9.

[29] Togay, O., Jeong, W.Y., Bishop, C.D. and White, D.W., "Towards a More Comprehensive Approach for Design Using Buckling Analysis", Proceedings, Annual Stability Conference, SSRC, 2015.

[30] White, D.W, Jeong, W.Y. and Togay, O., "Comprehensive Stability Design of Steel Members and Systems via Inelastic Buckling Analysis", Proceedings, 8th International Symposium on Steel Structures, 2015.

[31] Kucukler, M., Gardner, L. and Macorini, L., "A Stiffness Reduction Method for the in-plane Design of Structural Steel Elements”, Engineering Structures, 2014, Vol.73, pp. 72-84. 
[32] Kucukler, M., Gardner, L. and Macorini, L., "Lateral-torsional Buckling Assessment of Steel Beams through a Stiffness Reduction Method", Journal of Constructional Steel Research, 2015, Vol. 109, pp. 87-100.

[33] Kucukler, M., Gardner, L. and Macorini, L., "Flexural-torsional Buckling Assessment of Steel Beam-columns through a Stiffness Reduction Method”, Engineering Structures, 2015, Vol. 101, pp. 662-676.

[34] Kucukler, M., Gardner, L. and Macorini, L., "In-plane Design of Steel Frames through a Stiffness Reduction Method", Journal of Constructional Steel Research, 2015.

[35] Gardner, L., "Design of Steel Structures to Eurocode 3 and Alternative Approaches", Proceedings, International Symposium on Advances in Steel and Composite Structures, 2015, pp. 39-51.

[36] Shayan, S., "System Reliability-Based Design Of 2D Steel Frames By Advanced Analysis", PhD Thesis, School of Civil Engineering, University of Sydney, 2014.

[37] Cardoso, F.S., "System Reliability-Based Criteria for Designing Cold-Formed Steel Structures By Advanced Analysis", PhD Thesis, School of Civil Engineering, University of Sydney, 2016.

[38] Standards Australia, “AS4084, Steel Storage Racking”, 2012.

[39] Zhang, H. and Rasmussen, K.J.R., "System-Based Design For Steel Scaffold Structures Using Advanced Analysis", Journal of Constructional Steel Research, 2013, Vol. 89, pp. 1-8.

[40] Trahair, N.S., "Flexural-Torsional Buckling of Structures", E and F N Spon, 1993.

[41] Trahair, N.S., "Strength design of cruciform steel columns", Engineering Structures, 2012, Vol. 34, pp. 307-313

[42] Trahair, N.S. and Rasmussen, K.J.R., "Flexural-torsional Buckling of Columns with Oblique Eccentric Restraints", Journal of Structural Engineering, ASCE, 2005, Vol. 131, No. 11, pp. $1731-7$.

[43] Trahair, N.S. and Kayvani, K., "Capacities of Steel Columns with Excessive Crookedness", The Structural Engineer, 2006, Vol. 84, No. 4, pp. 37-41.

[44] Zhao, X.-L., Hancock, G.J. and Trahair, N.S., "Lateral Buckling Tests of Cold-formed RHS Beams", Journal of Structural Engineering, ASCE, 1995, Vol. 121, No. 11, pp. 1565 - 1573.

[45] Pi, Y.L. and Trahair, N.S., "Lateral Buckling Strengths of Cold-formed Rectangular Hollow Sections", Thin-Walled Structures, 1995, Vol. 22, No. 2, pp. 71-95.

[46] Trahair, N.S., "Inelastic Buckling Design of Monosymmetric I-beams", Engineering Structures, 2012, Vol. 34, pp. 564-71.

[47] Trahair, N.S., "Distortional Buckling of Overhanging Monorails", Engineering Structures, 2010, Vol. 32, pp. 982-7.

[48] Trahair, N.S., "Design of Steel Single Angle Lintels", Journal of Structural Engineering, ASCE, 2009, Vol. 135, No. 5, pp. 539-45.

[49] Pi, Y.L. and Trahair, N.S., "Inelastic Bending and Torsion of Steel I-beams", Journal of Structural Engineering, ASCE, 1994, Vol. 120, No. 12, pp. 3397-3417.

[50] Trahair, N.S. and Papangelis, J.P., "Flexural-Torsional Buckling of Monosymmetric Arches", Journal of Structural Engineering, ASCE, 1987, Vol. 113, No. 10, pp. 2271-2288.

[51] Pi, Y.L. and Trahair, N.S., "In-plane Buckling and Design of Steel Arches", Journal of Structural Engineering, ASCE, 1999, Vol. 125, No. 11, pp. 1291-1298.

[52] Papangelis, J.P. and Trahair, N.S., "Buckling of Monosymmetric Arches Under Point Loads", Engineering Structures, 1988, Vol. 10, No. 4, pp. 257-264.

[53] Pi, Y.L. and Trahair, N.S., "Inelastic Lateral Buckling Strength and Design of Steel Arches", Engineering Structures, 2000, Vol. 22, No. 8, pp. 993-1005.

[54] Pi, Y.L., Bradford, M.A., Trahair, N.S. and Chen, Y.Y., "A Further Study of Flexural-torsional Buckling of Elastic Arches", International Journal of Structural Stability and Dynamics, 2005, Vol. 5, No. 2, pp. 163-183. 
[55] Pi, Y.L., Bradford, M.A. and Trahair, N.S., "Inelastic Analysis and Behaviour of Steel I-beams Curved in Plan”, Journal of Structural Engineering, ASCE, 1999, Vol. 126, No. 7, pp. 772-9.

[56] Papangelis, J.P. and Trahair, N.S., "Integrated Computer Analysis and Design of Steel Structures", Proceedings, 5th International Conference on Civil and Structural Engineering Computing, 1993, pp. 45-54. 